\title{
A process of developing an HRM framework based on qualitative study in Technology companies in Bangladesh and Malaysia
}

\author{
Tarnima Warda Andalib ${ }^{\mathrm{a}}$ \\ ${ }^{a}$ PhD Fellow \& Lecturer, Faculty of Technology Management, Universiti Malaysia Pahang, Malaysia
}

\begin{abstract}
In the corporate world, humans are treated as 'manpower' or 'resources that utilize other resources, however, this cannot be the only identity of humans or employees of the company. Rather, it must be considered that these employees are humans and humans have got certain rights those are to be fulfilled irrespective of every situation. Humans are beings not just mere resources. This is the time to understand this truth. Technological change has triggered and increased the standard of living but at the same time has deteriorated the humane values and inspired a profligate life style; therefore, the Standardized Human Rights policies like Universal Declaration of Human rights (UDHR) \& International Labour Organization (ILO) need to be implemented in the organization culture by understanding the attitudes, attributes of human resources. The purpose of this Study is to investigate the HRM policies of the Technology Companies of Malaysia \& of Bangladesh and to identify all the components and integrate all those components with the standardized Human Rights platforms, which are UDHR, ILO etc. To look for the behavior, attitude and analytical option of humans working inside the company due to technological advancements, changes and implemented HRM policies in the organization.
\end{abstract}

Keyword: Human Resources Management, Human Rights, Framework, ILO, UDHR, Techno Companies, Qualitative

JEL Code: L22, M50, 031

\section{(C) 2014 Published by SSBFNET}

\section{Introduction}

In business life, humans are treated as 'manpower' or 'resources that utilize other resources, however, this cannot be the only identity of humans or employees of the company. Rather, it must be considered that these employees are humans and humans have got certain rights those are to be fulfilled irrespective of every situation. Humans are beings not just mere resources. This is the time to understand this truth. After the Technology revolution, when various equipment and machineries got into the corporate organizations to enhance the entire process flow, various kinds of organizations and industries have been boomed eventually. Loads of people got involved in the job arena and eventually the targets of these industries became only profit earning. The organizations that have been equipped by technological equipment and that deals with the technological products in the market, have various policies that are

\footnotetext{
${ }^{\mathrm{a}}$ Corresponding author.
} 
created and implemented to meet these targets. This flourishment, development and inclusion of technological equipment in various organizations have changed various technical and inherent issues of the industries specially treatment towards the employees. Technology is an independent variable having a range of effects at different levels of analysis (individual, group, enterprise, and inter-organizational) on multiple organizational outcomes as the dependent variable (Orlikowski \& Scott, 2008). Technology is one the impacts for the organization. Therefore, it shows that Human Resources Management Policies are in place in the Technology Companies; however Human Rights Violation still occurs.

\section{Literature Review}

Humans or employees are very important resources considered by the company; they need to be controlled in a proper manner so that they can achieve the targets set by the companies for profit earning. Therefore, to control Humans, certain policies are being created initially, which are named as Human Resources Management. Nevertheless, while creating these policies the organizations forget that humans are not just mere resources but also humans that have some entitled rights. Therefore, in this process the organizations often overlook the Human rights oriented policies and as a result various conflicts arise. Thus, to avoid conflicts and to meet the needs of individual employees Human Rights Conventions must be applied in the HRM Policies. Strategic human resource management (SHRM) focuses on aligning internally consistent human resource management (HRM) practices to build employees' knowledge, skills, and abilities in an effort to support competitive strategies and achieve business objectives (Huselid, Jackson, \& Schuler, 1997; Becker \& Huselid, 1999; Wright \& Snell, 1991).

The cross-cultural multinational organizations implement some other alluring policies that work for a short-term period but fails in the long term like 'employee benefits package' or 'extra incentive package' or etc. According to the strategic human resource management (SHRM) literature, greater organizational effectiveness is achievable through the development of internally consistent bundles of human resource practices that are matched to the extended organizational context and business strategies. (Karen Holcombe Ehrhart, Beth G. Chung-Herrera, 2008).

There is undoubtedly a severe built-in relationship between the organizational culture and the employees or humans working in these organizations. Any organization is built up with humans and with the inherent mindsets of these humans, their cultural perspectives and their interests of works or we can say passion towards a particular work. Therefore, to understand the culture of any organization we need to understand the humans working inside it and any organization need to provide the necessary desired rights \& benefits to these humans to get the organization run as a profit holding and revenue earning company. Potential benefits for management include decreased labor costs, improved efficiency, increased market visibility, wider customer base, and other competitive advantages. The organization purposes and human resources manageability can be understood from organization behavior. Organizational behavior illustrates employees' values, assumptions, legends, rituals and stories that all about artifacts, values and assumption in organization (Keller, 2007). 
Customers are typically allowed greater control and access to the organization, and added or extended services can be offered with mini- mal expenditure.(Karen Holcombe Ehrhart, Beth G. Chung-Herrera,2008)

"The issues studied in this stream include research regarding the interplay between aspects of technology and various elements of organizational life, such as what meanings emerge to make sense of a new information system (e.g. Prasad, 1993), how do technological implementations entail the mutual adaptation of technology and organization (Leonard-Barton \& Deschamps, 1988), how does the use of electronic media get shaped by existing cultural norms and practices (e.g. (Markus, 1994), how do technologies serve as boundary objects to afford knowledge sharing across disparate communities (Bechky, 2003), how does the design and use of technology shift the nature of work (e.g. ('Boudreau \& Robey, 2005)." (Janet H. Marler, Sandra L. Fisher, 2012).

In the industrial world, human resources are considered as means to profiteering. Some companies claim that human resources are our best assets. But when it comes to implementation very large number of firms treat them as just a factor of production factor. Human beings have their concerns and rights to live in freedom and dignity while performing their tasks in the companies. As, Humans are the main factors of an organization that needs to be motivated and needs to be triggered to get the works done, the integrated or strategic HRM policies, that merges the connection with Standardized Human Rights Policies has got high significance in the Organization Cultural arena. According to ILO, Decent Work Agenda (2012) The International Labour Organization (ILO) is a United Nations agency dealing with labour issues, particularly international labour standards and decent work for all. The ILO registers complaints against entities that are violating international rules; however, it does not impose sanctions on governments (Kazi Stastna, 2011). Therefore, in this proposal the author wishes to emphasize the role of Human rights in the Human Resources Management Policies that need to be addressed inside any organization, specifically the focus would be in the technology industries to reduce conflicts and to raise profit of the company along with creating a balance platform where the human resources are going to enjoy the human rights thoroughly. It is time to surmount this indifference in view of recent international efforts to define illicit businesses for regulatory purposes (Edmund F. Byrne, 2011).

There is Convention on Protection of the Rights of Migrant Workers (2003) under ICCPR where 'freedom from slavery and prohibition from slave trade (art. 8)' has been mentioned. Nevertheless, the treatment towards humans/employees has been marked as a reason for the organizational conflicts as in many organizations in spite of the existence of the human resources management is there, discriminatory and non-professionalism has been observed. In various technical organizations, humans are recruited and engaged based on their education and skill sets. However they are treated not as human beings but as resources to be utilized. And the grievance of the recruited employees gets in, flourishes within and ultimately bursts out.

There are several trade unions to protect employees' rights that are obliged to follow ILO standards. Nevertheless, Trade unionists had little inclination to learn, invoke, and use international human rights standards to advance their cause. (Compa Lance, 2008). The author would like to put up several facts and figures along with the case studies to reveal the scenario of present world in different organizations. People are often described as 'our most important asset' 
in annual reports and company value statements. For some organizations, those are merely empty words that sound nice but are not translated into practice. Other companies however have a culture that clearly makes people the most important asset of the organization (Jean-Marie Hiltrop,1996). According to Kravetz (1988), such a culture can be built in a variety of ways, where the companies that demonstrate a strong concern for the personal needs of people.Also the author would like to showcase the world with present problems for this background ignorance and would try to give some suggestion on this aspect. Through this research the author would provide a framework that creates a linkage between the Strategic Policies of HRM and OB culture.

A Conceptual framework or model would be designed that will create linkage between all the necessary components of HRS (Human Rights Conventions) and HRM (Human Resource Management). The world of business is changing rapidly and becoming more and more complex everyday. The HR theories of the 1900's are no longer valid in the 2000's. So, in order to keep up with the changes, HR Professionals need to know how to manage the modern organizations and their younger and more dynamic Human Resources. The HR Professionals today are expected to understand the core, basic business and become a Strategic Partner of the Top Management. On the other hand, employees' expectation towards the HR Professionals is to be an Employee Champions who need to deal the employees in a humanitarian way to fulfill human rights. This framework will be made when the multiple case studies will be done when various cases and related components would be found. This framework will be found when the factors can be identified after the data collection \& data analysis phase. This framework would create the linkages between the today's Human Resource Management situations with the Human Rights Conventions of Universal platforms.

\section{Researh Methodology}

For this paper, data will be collected in two ways; Secondary data and Primary data. For Primary data collection qualitative methods are going to be used specifically:

1. Focus groups discussion (FGD)

2. Multiple Case Studies (MCS)

a. Semi Structured Individual Interviews (SSII)

b. Observations

\subsection{Why Qualitative Why not Quantitative Method?}

Miles and Huberman (1984) have outlined specific techniques for analyzing qualitative data. Their ideas include a variety of devices such as tabular displays and graphs to manage and present qualitative data, without destroying the meaning of the data through intensive cod- ing. (Eisenhardt,1989). Data in the qualitative research contains the authenticity.

Quantitative evidence can indicate relationships those may not be salient to the researcher. It also can keep researchers from being carried away by vivid, but false, impressions unless the researchers corroborate those findings from 
qualitative evidence. The qualitative data are useful for understanding the rationale or theory-underlying relationships revealed in the quantitative data or may suggest directly theory which can then be strengthened by quantitative support (Jick, 1979; Mintzberg,1979).

Qualitative research focuses on Subjectivity, interpretations and context which are inevitably interwoven in every research project. No elements are dissolved or eliminated in quantitative research. (Melissa Emily Graebner, 2001).

\subsection{Relating the reasons with the Research}

In this research, where we are talking about Human Rights Deprivations or Violations issues, it has to be handled in a very delicate manner because it is a very sensitive issue. Here, there is no place for dubiousness or counterfeit data or information. The data has to be genuine, authentic and meaningful. And most importantly, this research will be constructing a theory, a conceptual framework where rational observation of all the previous theories and collected data must play a genuine role. The rational evidences and observations of data will be reflecting the relationships with the theory in a direct manner.

\subsection{Significance for Choosing the Qualitative Method:}

All types of evaluation require information that is gathered (data collection), grouped and analyzed. In this research, Qualitative data collection method will be followed. Qualitative data collection method has got some major benefits, which are:

Qualitative data cover a wide variety of information and research methods that most often take the form of written or verbal statements that are collected using unstructured or semi-structured interviews or questionnaires (Crabtree \& Miller, 1992).

In some cases such open-ended questions may be quantified, but in other cases these responses are analyzed using qualitative methods (Crabtree \& Miller, 1992).

Qualitative methods can be an important adjunct to an evaluation. When collecting quantitative data one often feels too remote from the participants to understand what their responses mean.

Qualitative methods, in contrast, try to obtain a rich amount of information about an individual so that the individual's ideas, opinions and experiences can be understood in more detail (Crabtree \& Miller, 1992).

Qualitative methods concentrate on words and observations to express reality and attempts to describe people in natural situations(Robert K.Yin,2012).

3.3.4 Questioning and generating Hypothesis:

Qualitative hypothesis-generating research involves collecting interview data from research participants concerning a phenomenon of interest, and then using what they say in order to develop hypotheses. It uses the two principles of (1) questioning rather than measuring and (2) generating hypotheses using theoretical coding (Carl F.Auerbach, Louse B. Silverstein, 2013) 
Studies the subjective experiences to construct theoretical saturation, it is likely that the qualitative researcher would have generated several relevant hypotheses that could be tested.

The qualitative research paradigm assumes that the best way to learn about people's subjective experience is to ask them about it, and then listen carefully to what they say. People almost always talk about their experience in a storied form. Thus, qualitative research is based on textual data rather than quantitative data, on stories rather than numbers. (Carl F.Auerbach, Louse B. Silverstein, 2013)

It allows for Naturalistic Observation, Description, Rather Than Testing General Laws. The qualitative approach begins with naturalistic ob- servation, that is, detailed description of the phenomenon being studied. Naturalistic observation is useful, not only to identify the lived experiences of the individuals being studied, but also to understand the relevant con- texts (social, racial, economic, etc.) of the experiences (Carl F.Auerbach, Louse B. Silverstein, 2013)

\subsubsection{A Tool for Studying Diversity:}

Qualitative research is particularly well suited to the study of diversity because it does not assume that there is one universal truth to be discovered, but rather focuses on lis- tening to the subjective experience and stories of the people being studied. (Carl F.Auerbach, Louse B. Silverstein, 2013)

Uses the Research Participants as Expert Informants:

It clarifies how qualitative researchers can study diversity without first formulating general hypotheses. It does so by encouraging the re- searcher to abandon the "expert" stance and treat the research participants as experts on their own lives. It encourages researchers to focus on learn- ing from the people they study. $\left({ }^{21}\right.$ Carl F.Auerbach, Louse B. Silverstein, 2013)

Involves Reflexivity; the Explicit Use of the Researcher's Subjectivity and Values:

It assumes that subjectivity and values are a necessary part of human in- teraction and therefore cannot be eliminated or controlled. It requires, in- stead, that researchers acknowledge their own subjectivity and values, and reflect on them in a systematic and disciplined way. In addition, qualitative researchers believe that their own subjective experience can be a source of knowledge about the phenomenon they are studying. Examining the way one's own subjectivity influences one's research is called reflexivity, and is a goal of qualitative research (Carl F.Auerbach, Louse B. Silverstein, 2013)

\subsection{Significance for using Focused Group Discussion:}

3.4.1 Focused group for induction method:

FGD discussion is used to apply the induction method and reduce the scattered ideas to find the more related ones: A focus group is a small group of people that is chosen (not randomly) because they are typical of the people that you are concerned about or who have a stake in the program (e.g., members of the target group, family members, treatment professionals). The focus group might begin with a general discussion that includes all participants, followed by a 
breakout procedure in which subgroups are put together to focus on specific issues. The smaller groups are then usually brought back together and the ideas from each subgroup as discussed. Ideas can be recorded on a flip chart, then the participants can discuss and evaluate the importance of each idea. A focus group for a gambling treatment process might address issues such as perceived barriers to treatment, client retention, addressing the clients' needs and developing appropriate outcome measures. (Morgan \& Krueger, The Focus Group Kit).

3.4.2 Semi Structured questionnaire will be made after the focused group discussion sessions: When collecting qualitative data it is recommended that the interview or focus group be audiotaped. This allows the interviewer or focus-group leader to make other "field notes" during the interview or focus group, while being able to review the audiotape at a later date. There are excellent manuals that describe the process of conducting a focus group in a stepby-step fashion (e.g., Morgan \& Krueger, The Focus Group Kit).

3.4.3 This discussion corrects, broadens and deepens the researchers' understanding of the participants' subjective experience: The focus group interviews are audiotaped or videotaped, the tapes are transcribed, and the transcript is analyzed by a group of four researchers: ourselves, the focus group interviewer, and another graduate student involved with the project. (Carl F.Auerbach, Louse B. Silverstein, 2013)

\subsection{Significance for choosing multiple case studies:}

Multiple case studies can employ an embedded design, that is, multiple levels of analysis within a single study. (Yin, 1984)

Finalize the components or variables for the outcome framework: Multiple Case Studies are applied to find the necessary components for the Conceptual Framework to clearly identify the linkages between the components as well as to develop and design the conceptual framework.

Logical Chain of evidence established: In order to understand the how and why associated with this project and hence to provide answers to our research questions, a logical chain of evidence (Yin, 1989) needed to be established. This chain of evidence was built in several steps. The first task was to identify the challenges, problems, deviations encountered during research work. Challenges were identified through an in-depth analysis of the contextual conditions surrounding the implementation project. In turn, for each challenge we described the tactics adopted to cope with the problems encountered, whether anticipated or not. The extent to which each deviation was overcome was explained by providing evidence of the effectiveness or impact of each coping tactics by identifying and explaining its adoption processes or prevention to adoption processes.

Indicates the link between the content of the protocols and research questions: Yin (1989) recommended each chain of evidence needs establishment of sufficient citations in the report to the relevant portions of the case study database and developing a case study protocol that clearly indicates the links between the content of the protocol and the initial research questions. Inspired by Eisenhardt (1989) the following flow chart of research methodology will give a glimpse look on the total research steps. 


\section{[Insert Table 1]}

\subsection{Data Collection Steps Description}

Secondary Data Collection: Concerns and previous studies of various researchers in the similar field along with the universal conventions.
a. Universal Covenants or documents of UDHR
b. Universal Document of ILO
c. Universal Document of AHRC
d. Newspapers
e. Dissertation Papers
f. Journals

\section{Primary Data Collection:}

In this research the qualitative methods are taken for collecting data. Data will be collected mainly by focused group discussion and multiple case studies the main data will be collected. Visiting few Technology Companies (Telecommunication Companies, Manufacturing Companies, IT Companies) Organizations and finding out information, data in two particular ways.

Firstly there will be focused group discussions on wide range of sample size and respondents to understand if Human Rights Violation Occurs or not, if so then in what degree and also to understand if the Company HRM policy supports UDHR convention or not. Step 1 to 4 will be undertaken in here.

Concentrate on manufacturing companies, IT service companies and telecommunication companies and select random executives for FGD. The random sample size here is $n 1$. Several Focused group discussions (there will be a semi structured questionnaire in the backend) will happen among the companies.

Findings (SSI questionnaire for the Multiple Case Studies, Impacts, Problems, Deviations or Factors, Areas, Components where Human rights violation occur).

Therefore;

$$
\mathrm{FGD}=(\mathrm{P}+\mathrm{I}) \text { for } \mathrm{n} 1
$$

Secondly, the companies would be chosen based on these findings of focused group discussion and also the questionnaire would be designed on which particular cases can be chosen and interviews can be taken of. Steps 5 and 6 will be undertaken in here.

Select specific companies based on the impacts, deviations and problems found in the focused group discussion. Selected Companies (Comp) $=$ Companies with $I+P$ 
Select specific cases on which this research can elaborate and dig down like Employee Benefits cases, employee Satisfaction Survey, Managers Evaluation Results and etc. Selected Cases (Sc) $=$ Cases with I+P in Comp.

Thirdly, Multiple case studies would be undertaken here the main two kinds of methods would be applied SSII (Semi Structured Individual Interviews) and Observation to understand the components of Organization Culture, HRM Policies and Organization Structure and then to compare those with the previewed literature review. Steps 7 to 11 will be undertaken in here.

A number of Interviews per company to be taken per company with semi structured questions. The interviewees will be Top Level managers, Mid Level Managers, General Employees, Trainers, Labours or Third Party Staffs (Technicians, Drivers, Union Representative, Plumbers, Assistants, Cleaners etc). The sample size here is n2. These interviews will provide qualitative data, holistic information for analysis.

The Organogram, HRM Policies, Organization's culture, structure and Components for the Conceptual Framework would be understood from this information as well. (Findings).

Therefore;

$\mathrm{MCS}=(\mathrm{LR} 2+\mathrm{Dc})$ for $\mathrm{n} 2$

Finally, After finding the components the framework development work starts, hypothesis is shaped, all the processes enfolds the literature and reaches to closure. Steps 12 to 15 would be undertaken in here.

Therefore;

$\mathrm{Gp}=\mathrm{fn}(\mathrm{FDD})+\mathrm{fn}(\mathrm{MCS})$

\section{Data Analysis}

Analyzing data is the heart of building theory from case studies, but it is both the most difficult and the least codified part of the process (Eisenhardt, 1989).

4.1 What is Coding?

A technique to analyze the qualitative data, those are collected from different qualitative methods. Carl F. Auerbach and Louise B. Silverstein has mentioned coding as a 'Adrift in a sea of data' and thus while creating the coding mechanism two issues have to be considered mainly in coding, one is research concern and second is the raw text. Depending on these two considerations few steps while developing the coding mechanism will be taken place. According to Auerbach and Louise, the six steps are as followings:

Understanding and selecting data for coding

Small Steps toward understanding the data :

a. Research concerns,

b. Theoretical Narrative 

c. Theoretical constructs
d. Themes
e. Repeating Ideas
f. Relevant Text
g. Raw Text

Selecting the data

a. Identify Repeated concerns, themes, theories, ideas, texts

b. Select the identified data

\subsection{Constructing coding mechanism}

According to Carl F. Auerbach and some researchers the qualitative data analysis needs some mechanism, which can be divided into three phases as followings.

\subsection{Developing Theory}

The above following phases lead to several steps that is discussed in the following.

Step 1: Explicitly State Your Research Concern and Theoretical Framework: The research concern is what the researcher wants to learn and identifies the reasons behind it. The Theoretical Framework is the set of believes about psychological and social processes with which the research study is approached.

Step 2: Select the Relevant Text for Further Analysis: Relevant text refers to passages of the transcript that expresses a distinct idea related to the research concerns.

Step 3: Discover Repeating Ideas by Grouping Together Related Passages of Relevant Text:

Working on Each Transcript Separately: A repeating idea is an idea expressed in relevant text by two or more research participants.

Discard data, which are Orphans, ideas too broad, ideas too narrow.

Give second thoughts.

Creating Your Master List of Repeating Ideas

The Collaborative Coding Process

Step 4. Organize Themes by Grouping Repeating Ideas into Coherent Categories: A theme is an implicit idea or topic that a group of repeating ideas have in common.

Step 5: Develop Theoretical Constructs by Organizing Themes into More Abstract Concepts: A theoretical construct is an abstract concept that organizes a group of themes by fitting them into a theoretical framework. 
Step 6: Create a Theoretical Narrative by Retelling the Participant's Story in Terms of Theoretical Constructs: A theoretical narrative describes the process that the research participants reported in terms of your theoretical constructs. It uses your theoretical constructs to organize people's subjective experience into a coherent story. It employs people's own language to make their story vivid and real.

Crafting Instruments and Protocols and Triangulation Process

Theory-building researchers typically combine multiple data collection methods. While interviews, observations, and archival sources are particularly common, inductive researchers are not confined to these choices. Some investigators employ only some of these data collection methods (e.g., Gersick, 1988, used only observations for the first half of her study), or they may add others (e.g., Bettenhausen \& Murnighan, 1986, used quantitative laboratory data).

The rationale is the same as in hypothesis-testing research. That is, the triangulation made possible by multiple data collection methods provides stronger substantiation of constructs and hypotheses (Eisenhardt, 1989)

\subsection{Data Reliability, Validity and Generalizability}

Smith \& Deemer (2000) has talked about data reliability, validity and generalizability. Qualitative research addresses the issues of reliability and validity in a way that contrasts with a quantitative approach. As suggested by Rubin \& Rubin (1995), we have established a procedure which is transparent (an- other investigator can know and check what we have done; communicable (the categories made sense to both the participants themselves, and to other investigators who want to use them); and coherent (the categories were simultaneously internally consistent, as well as reflective of both individual differences and genuine inconsistencies in the culture).

Carl F. Auerbach and Louise B. Silverstein stated that for qualitative research 'justifiability of interpreter' is alternative of 'reliability and validity' and 'transferability of theoretical construct' is alternative of 'generalizability'. Validation means a scale measures what if requires measuring comparison with another valid scale.

\section{5 'Justifiability of interpreter', alternative of 'reliability and validity'}

Use interpretations, subjectivity in analyzing the data but not justifiable to impose own subjectivity in an arbitrary manner means not grounded in data. Justifiability means not based on prejudices and doesn't bias the participants' experiences. Researcher's views and participants; experiences must be justifiable in qualitative research. To distinguish between justifiable and unjustifiable ways of using subjectivity to interpret data three criteria are necessary.

The criteria are transparency, communicability and coherence $\left({ }^{29}\right.$ Rubin and Rubin, 1995). Each of these criteria involves making use of other people to check against use tendency to impose one's own subjectivity biases on the data analysis.

Transparency: Other researchers know the steps by which you have arrived at your interpretation. It doesn't mean agreeing with the interpretation but they know how you arrive to it. Keeping records of what you've done. 
Communicability: Themes and Constructs are understood by other researchers and to the research participants themselves. It doesn't mean everyone has to agree with you but all must understand what you do.

Coherence: Theoretical constructs must fit together and allow you to tell a coherent story, It doesn't mean the developed story would be the only possible one but it helps to organize the data. Data analysis procedure helps you to produce coherent ideas by developing constructs that fit into an organized theoretical narrative.

\subsection{Transferability alternative of 'Generalizability'}

The theoretical constructs in grounded theory have abstract pattern, found from diverse situations. It cannot be considered as generalizability but transferable that provides guidelines not exact rules and regulations.

Theoretical sampling's goal is to create transferable constructs about research concerns. For achieving these goals indepth exploration of constructs from different contexts are needed. For selecting the sample size theoretical saturation is needed. $\left({ }^{30}\right.$ Carl F.Auerbach, Louse B. Silverstein, 2013)

Data Analysis Tool: NVivo helps to manage, analyze and report on unstructured data. This is the tool used for analyzing the Qualitative Data.

\section{Conclusion and Discussion}

Various researchers have worked on human rersources management issues in the corporate arena focusing on the work life, working conditions, employees' benefits, employee's satisfaction or frustration, employee health issues and etc. In this research because I have focused on Bangladesh and Malaysian companies, I have found some information through their research that are useful for my research and framework development. Some of the findings are in the following.

\section{[Insert Table 2 ]}

In this research, the existing HRM policies of the Malaysian \& Bangladeshi Technology Industries are going to be understood by observation and analysis of the existing HRM components inside the companies. Technological advancements and various changes are incorporated with the HRM policies of the companies. But, whether the employees accept these changes or not and whether these changes are affecting the employees in their lifestyles, attitudes or not these are also thoroughly analyzed in this research. The conflict issues inside the organizations indicate another area that how human rights are violated inside the companies. All these HRS components are identified and are integrated with the components of HRM so that the framework can support the work environment in a proper way, can reduce all the conflicts and also can help the companies to increase the profit making and revenue earning by maintaining the production area with proper humane values.

The outcomes of the study entail several Implications of Human Resource Management Policies in the technology companies of Malaysia. 
- To address the development issues of Human Resources Management Policies so that the Technological companies can improve the 'Employee Factors' inside the Companies

- To find out the factors that will create job satisfaction among the employees by minimizing organizational conflicts

- To identify the relationship linkages with the HRM factors and Universal Platform's Human Rights factors so that these can be integrated to create a better HRM platform that will resolve all Human resources oriented issues

The main goal of this research is to make the HRM managers incorporating the Framework with the company policies and make the HRM policy standard world-wide to develop a good atmospheres \& healthy culture of the organization by reducing conflicts.

\section{Acknowledgement:}

First of all, I wish to thank my honorable supervisor 'Dr. Ridzuan Bin Darun' who guided me all throughout my research; without his advices. I want to also thank my Co-supervisor 'Dr. Azlina Azizan and my Fellow colleague 'Alaaeldeen Saleh M Al Adresi' for their contribution and assistance. I wish to thank my mother 'Dr. Dil Rowshan Zinnat ara Nazneen' who has been beside me all the time to give me mental support to carry on with all loads and also I wish to thank my dearest friend 'Sadia Rahman Boby' for her all support for which I have been able to carry on with the research work loads inspite of many adversaries. I wish to thank also my Grandpa 'Prof. Emajuddin Ahamed' for his believe in me all throughout. I also wish to thank Universiti Malaysia Pahang (UMP), Malaysia for giving the opportunity and support to do my research. Finally, I wish to thank to my Almighty Allah for giving me strength, courage and patience to go on with the research.

\section{References}

Bashein, B. J., Markus, M. L., \& Riley, P. (1994). Preconditions for BPR success and how to prevent failures. Information System Management, 11(2), 7-13.

Bechky, B. A. (2003). Object Lessons: Workplace Artifacts as Representations of Occupational Jurisdiction1. American Journal of Sociology, 109(3), 720-752.

Becker \& Huselid (1999). Overview: Strategic human resource management in five leading firms, Human resource management, 38 (4), 287-301

Bettenhausen, K., \& Murnighan, J. K. (1986) The emergence of norms in competitive decision-making groups. Admin- istrative Science Quarterly, 30, 350-372.

Boudreau, M. C., \& Robey, D. (2005). Enacting integrated information technology: A human agency perspective. Organization science, 16(1), 3-18.

Carl Auerbach, Louise B. Silverstein(2003). Introduction to Coding and Analysis. NYU Press

Crabtree B.F. \& Miller, W.L (1992). Doing qualitative research: Research Methods. Sage Publications, Newbury Park, Vol:3

Edmund F. Byrne (2011). Business Ethics Should Study Illicit Businesses: To Advance Respect for Human Rights. Journal of Business Ethics 103 (4):497-509.

Gallhofer, S., Haslam, J. and Walt, S. (2011). Accountability and transparency in relation to human rights: A critical perspective reflecting upon accounting, corporate responsibility and ways forward in the context of globalization. Critical Perspectives of on Accounting 22, 765 - 780. 
Gersick,C.J.G.(1988). Time and transition in work teams: Toward a new model of group development, Academy of Management Journal, 31, 9-41.

Henry Mintzberg (1979) An Emerging Strategy of "Direct" Research", Administrative Science Quarterly, Vol. 24, No. 4, 582-589

Huselid, Jackson, \& Schuler, (1997). Technical and strategic human resource management effectiveness as determinants of firm performance. Academy of Management Journal, 40, 171-188.

Janet H. Marler, Sandra L. Fisher(2012) An evidence-based review of e-HRM and strategic human resource management. Human Resource Management Review, HUMRES-00418; No of Pages 19 (2012).

Jean-Marie Hiltrop(1996). A Framework for Diagnosing Human Resource Management Practices.European Management Journal Vol. 14, No. 3, 243-254.

Jick, T. (1979). Mixing qualitative and quantitative methods: Triangulation in action, Administrative Science Quarterly, 24.

Karen Holcombe Ehrhart, Beth G. Chung-Herrera( 2008). HRM at Your Service: Developing Effective HRM Systems in the Context of E-Service. Organizational Dynamics, Vol. 37, No. 1, 75-85,

Kathleen M. Eisenhardt (1989).Building Theories from Case Study Research, The Academy of Management Review, Vol. 14, No. 4.532-550.

Kazi Stastna (2011). Government's recent labour interventions highly unusual, experts say. CBC News

Kevin Lane Keller, (2007). Strategic Brand Management : Building, Measuring, and Managing Brand Equity, International Edition

Kravetz, Dennis J. (1988). The human resources revolution: Implementing progressive management practives for bottom-line success.Jossey-Bass Publishers (San Francisco), 1st edition, 208 p.

Krueger, R. A. (1994). Focus groups: A practical guide for applied research (2nd ed.). Thousand Oaks, CA: Sage.

Leonard- Barton \& Deschamps, (1988). Implementation as mutual adaptation of technology and organization. Research Policy, (17).251-67

Melissa Emily Graebner, (2001) The Other Side of the Story: Seller Decision-making in Entrepreneurial Acquisitions. Stanford University, 342 pages

Miles, M. B., \& Huberman, M. (1994) Qatative data analysis: An expanded sourcebook , (2nd ed.) Thousand Oaks, CA: Sage.

Morgan, G. (1980).Paradigms, metaphors, and puzzle solving in organization theory. Administrative Science Quarterly, 25 (4): 605-622.

Orlikowski, W.J. and Scott S.V., (2008). Sociomateriality: Challenging the separation of technology, work and organization. Academy of Management Annals, 2 (1), 433-474.

Prasad, P. (2005). Crafting qualitative research: Working in the postpositivist traditions . Armonk, NY: M.E. Sharpe.

Robert K.Yin(2012).Applications of Case Study Research. Sage, 231

Rubin \& Rubin (1995). Qualitative interviewing: the art of hearing data, London: Sage Publications.

Sahari Salawati, Md Isa Abu Hassan Sharon, Cheuk Choy Sheung (2000). Corporate Reporting on Human Rights: Construction Companies in Malaysia., Journal Kemanusiaan Bil. 20

Smith, John K., \& Deemer, D. K. (2000). The problem of criteria in the age of relativism. In Norman K. Denzin \& Yvonna S. Lincoln (Eds.), Handbook of Qualitative Research, 2nd ed., (pp. 877-896). Sage: Thousand Oaks, California.

Wright \& Snell, (1991). Toward an integrative view of Strategic Human Resource Management. Human Resource Management Review, 1, 203-225.

Zhao, Z-Y., Zhao, X-J., Davidson, K. and Zuo, J. (2012). A corporate social responsibility indicator system for construction enterprises. Journal of Cleaner Production, doi:10.1012/j.jclepro.2011.12.036

http://www.ilo.org/integration/themes/mdw/lang--en/index.htm

http://en.wikipedia.org/wiki/Human_resources

http://humanresources.about.com/od/glossaryh/f/hr_management.htm

http://www.ilo.org/public/english/gender.htm 
Table 1: Research methodology Steps inspired from Eisenhardt (1989)

\begin{tabular}{|c|c|c|c|}
\hline & RM Steps & Activity & Reasons \\
\hline 1 & Start & Start the Project step & The starting point \\
\hline 2 & Do Literature Review & Collect Secondary data & $\begin{array}{l}\text { Finds issues on Human rights, ILO, UDHR, All } \\
\text { intl. HR organizations, HRM issues, Ref of } \\
\text { ORG culture, Org. Behaviour }\end{array}$ \\
\hline \multirow[t]{2}{*}{3} & \multirow[t]{2}{*}{$\begin{array}{l}\text { Discuss with the focused } \\
\text { groups }\end{array}$} & \multirow[t]{2}{*}{ Apply Inductive Data collection method } & $\begin{array}{l}\text { Finds problems/deviations of the org regarding } \\
\text { Human resources }\end{array}$ \\
\hline & & & Develop Interview Questions \\
\hline \multirow[t]{2}{*}{4} & \multirow[t]{2}{*}{ Select Companies } & $\begin{array}{l}\text { Select organizations that use Huge } \\
\text { machineries or IT equipment or } \\
\text { Telecommunication Networks used }\end{array}$ & $\begin{array}{l}\text { Information, Assumption of Human rights } \\
\text { deviation }\end{array}$ \\
\hline & & $\begin{array}{l}\text { Selects companies those have certain } \\
\text { deviations found from focused group } \\
\text { discussion }\end{array}$ & News /information of human rights deviation \\
\hline 5 & $\begin{array}{l}\text { Do Background study of } \\
\text { the companies }\end{array}$ & $\begin{array}{l}\text { Collect Primary \& Secondary data of the } \\
\text { companies (Annual publication) }\end{array}$ & $\begin{array}{l}\text { Before doing the multiple case studies of the } \\
\text { companies do background study }\end{array}$ \\
\hline \multirow[t]{2}{*}{6} & \multirow[t]{2}{*}{ Selecting Cases } & Specify Population & Sharpens external validity \\
\hline & & Select Theoretical sampling & $\begin{array}{l}\text { Focuses efforts on cases that replicate or extend } \\
\text { theory }\end{array}$ \\
\hline \multirow[t]{4}{*}{7} & \multirow[t]{4}{*}{ Do Multiple Case Studies } & Craft instruments and protocols & $\begin{array}{l}\text { finds HRM Policies and cases of employee } \\
\text { dissatisfaction }\end{array}$ \\
\hline & & Apply Multiple data collection methods & $\begin{array}{l}\text { Strengthens the research objective with } \\
\text { evidences }\end{array}$ \\
\hline & & Apply Qualitative method & Synergistic view of evidence \\
\hline & & Select Multiple investigators & $\begin{array}{l}\text { Fosters divergent perspectives and strengthens } \\
\text { grounding }\end{array}$ \\
\hline 8 & Entering the field & Analyze the Overall data collection process & $\begin{array}{l}\text { Speeds analysis and reveals helpful adjustments } \\
\text { to data collection }\end{array}$ \\
\hline 9 & $\begin{array}{l}\text { Take Semi Structured } \\
\text { Individual Interviews }\end{array}$ & Develops interview questions & $\begin{array}{lr}\text { Finds HRM Policies } & \text { Finds cases } \\
\text { of Employee satisfaction } & \text { Finds } \\
\text { Organogram } & \end{array}$ \\
\hline 10 & Do Some Observation & $\begin{array}{l}\text { Finds out information informally and from } \\
\text { archieve }\end{array}$ & Finds Gap between HRM Policies and practices \\
\hline 11 & $\begin{array}{l}\text { Identify the components } \\
\text { of Conceptual Framework }\end{array}$ & $\begin{array}{l}\text { finds the HRM components and } \\
\text { components where deviation occurs }\end{array}$ & helps to build the theory \\
\hline 12 & $\begin{array}{l}\text { Start Creating the } \\
\text { Conceptual Framework }\end{array}$ & $\begin{array}{l}\text { joins the components from research study } \\
\text { and also from the components from Human } \\
\text { rights study }\end{array}$ & Builds the theory \\
\hline 13 & Shaping hypotheses & $\begin{array}{l}\text { Replication, not sampling, logic across } \\
\text { cases }\end{array}$ & Confirms, extends and sharpens theory \\
\hline & & $\begin{array}{l}\text { Search evidence of 'why' behind } \\
\text { relationships }\end{array}$ & Build Internal validity \\
\hline 14 & Enfolding literature & Comparison with conflicting literature & Builds internal validity \\
\hline & & Comparison with similar literature & Sharpens generalizability \\
\hline 15 & Reaching closure & Theoretical saturation when possible & $\begin{array}{l}\text { Ends process when marginal improvement } \\
\text { becomes small }\end{array}$ \\
\hline
\end{tabular}


Table 2: Researchers' Explanations and HRM Component on Country Basis

\begin{tabular}{|c|c|c|c|}
\hline Issues & Researchers' Explanations & HRM Component & Country \\
\hline 1 & $\begin{array}{l}\text { Working conditions in the RMG sector frequently violate } \\
\text { international labour standards, and Codes of Conduct (Qudus } \\
\text { and Uddin S., 1993; Dasgupta S., 2002). }\end{array}$ & Working conditions & Bangladesh \\
\hline 2 & $\begin{array}{l}\text { Kumar (2006) focusses; Garments workers are concerned with } \\
\text { long working hours or double consecutive shifts, personally } \\
\text { unsafe workenvironment, poor working conditions, wage and } \\
\text { gender discrimination. Indeed, employers treat the RMG workers } \\
\text { as slaves, exploiting workers to increase their profit margins and } \\
\text { keep their industry competitive in the face of increasing } \\
\text { international competition (Kumar A., 2006). }\end{array}$ & $\begin{array}{l}\text { Working } \text { Conditions, } \\
\text { wage, gender } \\
\text { discrimination }\end{array}$ & Bangladesh \\
\hline 3 & $\begin{array}{l}\text { Formation of a trade union is often thwarted by severe } \\
\text { repression, dismissal, arrest, assault by hooligans hired by } \\
\text { employers, and other practices which are in violation of the } \\
\text { international labour standards } s_{5} \text { and Codes of Conduct (ILO, } \\
\text { 2003). }\end{array}$ & $\begin{array}{ll}\text { Assault, } & \text { Arrest, } \\
\text { Repression, } & \\
\text { Dismissal, } & \\
\text { Threatened } & \text { Trade } \\
\text { union } & \end{array}$ & Bangladesh \\
\hline 4 & $\begin{array}{l}\text { Bangladesh is considered to have the child labour problem } \\
\text { especially in the RMG sector. In most cases, children often } \\
\text { commence work at a very young age; as a result, they are } \\
\text { suffering serious injuries and sometimes death in the workplace } \\
\text { (Rahman, Khanam, and Nur 1999). }\end{array}$ & Child Labour & Bangladesh \\
\hline 5 & $\begin{array}{l}\text { According to the Factory Act 1965, a worker being employed for } \\
12 \text { months is entitled to annual leave, casual leave, sick and } \\
\text { medical leave, festival leave and maternity leave with pay which } \\
\text { are violated. (ILO and BGMEA, 2003; ILO, 2005). }\end{array}$ & Leave issues & Bangladesh \\
\hline 6 & $\begin{array}{l}\text { The significance of accounting disclosure regarding human } \\
\text { rights at work place of Malaysian organization was further } \\
\text { stressed by Gallhofer et al. (2011), where corporations effectively } \\
\text { violate human rights or are complicit in their violations. }\end{array}$ & $\begin{array}{l}\text { Accounting in terms } \\
\text { of Salary, benefits, } \\
\text { wages, Promotion }\end{array}$ & Malaysia \\
\hline 7 & $\begin{array}{l}\text { As for Gallhofer et al. (2011), the link between accounting and } \\
\text { human rights stresses on the issue of transparency and } \\
\text { accountability. }\end{array}$ & $\begin{array}{l}\text { Org's Accounting } \\
\text { Transparency \& } \\
\text { Accontability }\end{array}$ & Malaysia \\
\hline 8 & $\begin{array}{l}\text { It was found that } 70 \% \text { of the sample firms disclosed occupational } \\
\text { health and safety in their annual report. (Sahari Salawati, Md Isa } \\
\text { Abu Hassan Sharon, Cheuk Choy Sheung, 2000) }\end{array}$ & $\begin{array}{l}\text { Employees' } \\
\text { Occupational Health } \\
\text { \& Safety }\end{array}$ & Malaysia \\
\hline 9 & $\begin{array}{l}\text { Other human rights items include the prohibition of harassment } \\
\text { of the workers, abuse and corporal punishment (Zhao et al., } \\
\text { 2012). }\end{array}$ & $\begin{array}{l}\text { Employee } \\
\text { Harassment }\end{array}$ & Malaysia \\
\hline
\end{tabular}

